\title{
Impact of Specific Training in Detecting Osteoporotic Vertebral Fractures on Routine Chest Radiographs
}

\author{
Einfluss einer spezifischen Lehrinitiative auf die Detektionsrate von osteoporoti- \\ schen Wirbelkörperfrakturen in routinemäßigen Röntgenthoraxaufnahmen
}

Authors

Affiliations
M. Gruber ${ }^{1}$, J. Dinges ${ }^{2}$, D. Müller ${ }^{3}$, T. Baum4, E. J. Rummeny ${ }^{4}$, J. Bauer ${ }^{4}$

Department of Radiology, Division of Neuroradiology and Musculoskeletal Radiology, Medical University of Vienna

Departement of Nuclear Medicine, University Hospital Klinikum rechts der Isar, Munich

Department of Radiology, University Hospital Cologne

Department of Radiology, University Hospital Klinikum rechts der Isar, Munich

\author{
Key words \\ - spine \\ - vertebral fracture \\ - chest radiograph \\ - osteoporosis
}

eingereicht 17.9 .2012

akzeptiert 30.1.2013

Bibliography

DOI http://dx.doi.org/

10.1055/s-0033-1335230

Published online: 02.09.2013

Fortschr Röntgenstr 2013; 185:

1074-1080 @ Georg Thieme

Verlag KG Stuttgart · New York . ISSN 1438-9029

\section{Correspondence}

Herr Dr. Michael Gruber

Department of Radiology,

Medical University Vienna

Währinger Gürtel 18-20

1090 Vienna

Austria

Tel.: ++ 43/1/404004818

Fax: ++ 43/1/404004898

michael.gruber@meduniwien.

ac.at

\section{Abstract \\ $\nabla$}

Purpose: Vertebral fractures are the most common complication of osteoporosis. Routine chest radiographs are a potential screening method, but a significant under-reporting has been described previously. The purpose of this study was to evaluate the effect of a specific training on the detection rate of vertebral fractures of a radiology resident.

Materials and Methods: 936 routine lateral chest radiographs of postmenopausal women were evaluated by a radiology resident (R1) during clinical routine. After the evaluation of 470 radiographs (pre-training group), R1 underwent a specific training based on the teaching initiative of the IOF/ESSR. Afterwards the remaining 466 radiographs were evaluated (post-training group). As a standard of reference, all radiographs were reviewed by two radiologists in consensus (R2 +3 ). A semi-quantitative method (spinal fracture index, SFI) was used to assess vertebral fractures.

Results: Kappa-values as statistical measure of agreement between R1 and R2 +3 for the detection of vertebral fractures (Genant Severity $>0$ ) increased from $\mathrm{k}=0.311(95 \% \mathrm{CI}$ : $0.217-0.405$; “fair agreement") in the pretraining group to $\mathrm{K}=0,882$ (95\% CI: 0,835 0,929 ; "almost perfect agreement") in the post-training group. Similar results were observed for severe fractures (Genant Severity $>1$ ). Especially fractures with Genant Severity 1 were not detected by $\mathrm{R} 1$ before training.

Conclusion: A brief training is essential to increase the awareness of radiologists to correctly report osteoporotic vertebral fractures and may help to initiate appropriate therapy in patients with vertebral fractures.
Key Points:

- The awareness of radiologists regarding the correct reporting of vertebral fractures is in need of improvement.

- The detection of vertebral fractures improves with targeted training.

- The teaching initiative of the IOF/ESSR is suitable for this.

Citation Format:

- Gruber M., Dinges J., Müller D. et al. Impact of Specific Training in Detecting Osteoporotic Vertebral Fractures on Routine Chest Radiographs. Fortschr Röntgenstr 2013; 185: 1074-1080

\section{Zusammenfassung}

$\nabla$

Ziel: Wirbelkörperfrakturen sind die häufigste Komplikation der Osteoporose. In der klinischen Routine durchgeführte Röntgenthoraxaufnahmen stellen eine mögliche Screeningmethode dar, allerdings wurde die fehlende Beschreibung osteoporotischer Wirbelkörperfrakturen in der Routinediagnostik mehrfach kritisiert. Der Zweck dieser Studie war die Evaluation einer spezifischen Schulung auf die Detektionsrate von Wirbelkörperfrakturen eines Radiologen in der täglichen Befundung.

Material und Methoden: 936 routinemäßige Röntgenthoraxaufnahmen postmenopausaler Frauen wurden durch eine radiologische Assistenzärztin (R1) im Rahmen der Routine befundet. Nach der Auswertung von 470 Aufnahmen (Gruppe vor Training) nahm R1 an einer auf der Lehrinitiative von IOF/ESSR basierenden Schulung teil. Danach wurden die restlichen 466 Aufnahmen (Gruppe nach Training) befundet. Als Referenzstandard wurden alle Bilder von zwei Radiologen $(\mathrm{R} 2+3)$ einvernehmlich begutachtet. Es wurde ein semiquantitatives Verfahren (nach Genant) angewen- 
det, um osteoporotische Wirbelkörperfrakturen zu beurteilen. Ergebnisse: Der Kappa-Wert als statistisches Maß der Übereinstimmung zwischen R1 und R2+3 für detektierte Frakturen (Genant-Grad >0) stieg von $\mathrm{k}=0,311$ (95\% CI: 0,217-0,405) im Sinne eines „fair agreement" in der Gruppe vor Training auf $K=0,882(95 \%$ CI: 0,835-0,929) im Sinne eines ,almost perfect agreement" in der Gruppe nach Training. Ähnliche Ergebnisse wurden für mittlere/schwere Frakturen (Genant-Grad > 1) beobachtet. Insbesondere wurden vor Schulung Wirbelkörperfrakturen von Genant-Grad 1 übersehen.

Schlussfolgerung: Eine kurze Schulung ist notwendig und ausreichend, um das Bewusstsein eines Radiologen hinsichtlich korrekter Befundung von osteoporotischen Wirbelkörperfrakturen zu verbessern und somit dazu beizutragen, eine geeignete Therapie bei Patienten mit prävalenten Wirbelkörperfrakturen zu veranlassen.

\section{Introduction}

\section{$\nabla$}

As the world's population continues to age, osteoporosis is expected to become more prevalent and to entail considerable physical, psychosocial and financial consequences. The frequency of osteoporotic fractures and the resulting healthcare costs are increasing worldwide [3]. Hip and vertebral fractures are the most serious complications resulting from osteoporosis and are accompanied by decreased quality of life and increased mortality, regardless of other previously existing diseases such as ankylosing spondylitis [4-6]. A key aspect that makes vertebral fractures so critical is that their presence greatly increases the risk of additional fractures [7]. Vertebral fractures affect approximately $25 \%$ of postmenopausal women. Unlike hip or wrist fractures, however, they are often asymptomatic $[8,9]$.

The Fracture Risk Assessment Tool (FRAX) was developed by the World Health Organization (WHO) Task Force in 2008 to provide a prognostic tool for evaluating individual fracture risk that would in turn furnish general clinical guidelines for decisions regarding treatment [10]. In this computational tool, atraumatic fractures constitute an important risk factor. According to the guidelines of Germany's "Dachverband Osteologie" [Osteology Umbrella Organization] (DVO), prevalent osteoporotic fractures also have a major influence on further diagnostics and therapy [11]. Even more than FRAX, the guidelines of the DVO accordingly assign a critical role to vertebral fractures, giving them greater importance than the presence of other prevalent fractures.

While routine chest radiographs are a possible screening method, earlier studies have shown that approximately $32 \%$ of vertebral fractures were not described and necessary treatments were thus not initiated [12-17]. By initiating further diagnostic steps and appropriate therapy, the act of diagnosing osteoporotic fractures by means of any given radiological examination facilitates a reduction in healthcare costs, regardless of primary indication [18]. It also allows a significant reduction in the mortality and morbidity of the affected patients [19]. The "International Osteoporosis Foundation" (IOF) and "European Society of Musculoskeletal Radiology" (ESSR) have therefore launched a teaching initiative to raise awareness among radiologists on the importance of precisely documenting vertebral fractures. This teaching program [20] introduces, in addition to the radiological appearance of osteoporotic vertebral fractures and the differential diagnosis thereof, background information on epidemiology and clinical consequences.

The purpose of this study was to evaluate the influence of the teaching program of the IOF and ESSR on a radiologist's rate of detecting vertebral fractures from routine chest radiographs and raising awareness among radiologists on the importance of precisely documenting vertebral fractures.

\section{Material and methods \\ $\nabla$}

The retrospective study was conducted in accordance with the Declaration of Helsinki [21] and the guidelines of our institute regarding research on humans. Upon being admitted to the study, all patients gave their written declaration of informed consent for the scientific analysis of their imaging data.

Patients, imaging and image analysis

Nine hundred thirty six (936) routine posterior-anterior (p. a.) and lateral radiographs were taken from postmenopausal women over the age of 55 (average age 70.8, standard deviation (SD) \pm 9.0 ) by a radiologist in the second year of her residency (reader 1, R1) as part of routine hospital procedure. When the study commenced, the resident already had six months of experience at the thoracic station and had received appropriate training. The reports were then reviewed and released by the appropriate senior physician. Each radiograph was selected without any prior knowledge of clinical findings. All images were prepared with a digital flat image detector (Revolution XQ/i; General Electric Medical Systems, Milwaukee, WI, USA). The imaging parameters were identical for each patient, with a standard technique involving $120 \mathrm{kV}$ of tube voltage, $2.5 \mathrm{~mm}$ Al-tube filter aided by a raster (ratio 13:1, 70 lines per centimeter) and automatic exposure control being employed. Because of compromised vertebral column visibility, patients with severe scoliosis were excluded. After evaluating 470 radiographs (Group 1 (prior to training), average age 70.8 years, SD \pm 8.8 ), R1 underwent special training based on the teaching initiative of the IOF and ESSR [20]. The training was conducted by a radiologist experienced in the musculoskeletal system as part of the hospital's own continuing education program. Afterwards, the remaining 466 radiographs were evaluated as part of routine hospital procedure (Group 2 (after training), average age 70.8 years, $S D \pm 9.2$ ). To provide a reference standard, each radiograph was jointly evaluated by two radiologists (Reader 2 and 3, R2 + 3) possessing six and eight years' experience, respectively, and advanced knowledge in the area of radiology of the musculoskeletal system. They examined the subsequently randomized 936 images in a series of sessions each containing a maximum of 70 patients. Because these two specialists completed no training between the evaluations of both groups, the reference standard was identical for both groups.

All images were uploaded to the institute's "Picture Archiving and Communication System" (PACS, Sectra AB, Linköping, Sweden) and viewed on standard monochromatic liquid crystal display (LCD) monitors (MDL2105A, Totoku Electric Company Limited, Ueda, Nagano, Japan). The ambient light was dimmed and remained uniform for all evalua- 
tion sessions. Genant's semi-quantitative method [22] was used for evaluating the severity of vertebral fractures imaged on the radiographs from the second thoracic vertebra (T2) through the third lumbar vertebra (L3).

\section{Statistical analysis}

All statistical analyses were performed using Microsoft Excel (Microsoft Corp., Redmond, WA, USA) and SPSS (SPSS Inc., Chicago, IL, USA).

The number of patients in Groups 1 and 2with Genant severity $>0$ and Genant severity $>1$ vertebral fractures were computed for $\mathrm{R} 1$ and $\mathrm{R} 2+3$. Prevalence was computed both combined for the thoracic spinal column (TSC) and the upper lumbar spinal column (LSC) (T2 through L3) as well as separately for the TSC (T2 through T12) and the upper LSC (L1 through L3).

The number of patients diagnosed by $\mathrm{R} 2+3$ with osteoporotic vertebral fractures (Genant severity $>0$ as well as Genant severity $>1$ ) and the total number of Genant severity $>0$ as well as Genant severity $>1$ fractures from T2 through L3 in the Group 1 and 2 patients were compared using the chi-square test. This was done to ensure that the comparison of the results of R1 prior to and following the training was not distorted by a difference in prevalence and distribution of osteoporotic vertebral fractures in Groups 1 and 2 .

The agreement between R1 and R $2+3$ prior to and following the training was computed as a simple percent agreement and as Cohen's kappa with a 95\% percent confidence interval (95\%). The agreement among the readers was ascertained both combined for TSC and LSC (T2 through L3) as well as sep- arately for the TSC (T2 through T12) and LSC (L1 through L3). Improved detection of osteoporotic vertebral fractures by R1 as a result of the training was measured through a better agreement between $R 1$ and the reference standard $(R 2+3)$. A statistically significant improvement in agreement was defined by an increase and not overlapping $95 \%$ CI of $\mathrm{k}$ in Group 2 over Group 1. To obtain a statistical measurement for improved agreement, the classification of the kappa values according to Landis et al. was used [23], with $<0$ being "poor agreement", 0 to 0.20 being "slight agreement", 0.21 to 0.40 being "fair agreement", 0.41 to 0.60 being "moderate agreement", 0.61 to 0.80 being "substantial agreement" and 0.81 to 1.00 ibeing "almost perfect agreement".

The spinal fracture index (SFI - average fracture severity according to Genant et al. [22]) of all examined vertebrae (T2 through L3) was additionally computed for each patient. The differences in SFI between R1 and R2 + 3 were compared for groups 1 and 2 using the Wilcoxon sign rank test.

\section{Results}

$\nabla$

An analysis of the reference standard appraisal of $R 2+R 3$ showed that there were no statistically significant differences in terms of the number of patients with Genant severity $>0$ fractures (Group 1: 117, Group 2: 140; p=0.078; $\bullet$ Tab. 1) as well as Genant severity > 1 moderate/severe fractures (Group 1: 67, Group 2: 63; $\mathrm{p}=0.078$; Table 1). The total number of Genant severity $>0$ as well as Genant severity $>1$ fractures from T2 through L3 in patients from groups 1 and 2 likewise

\begin{tabular}{|c|c|c|}
\hline & $\begin{array}{l}\text { number of patients with fractures } \\
\text { having a Genant severity }>1\end{array}$ & $\begin{array}{l}\text { number of patients with fractures } \\
\text { having a Genant severity }>0\end{array}$ \\
\hline \multicolumn{3}{|l|}{ T2-L3 } \\
\hline R1 Group $1(n=470)$ & 33 & 33 \\
\hline$R 2+3$ Group $1(n=470)$ & 67 & 117 \\
\hline R1 Group $2(n=466)$ & 58 & 118 \\
\hline$R 2+3$ Group $2(n=466)$ & 63 & 140 \\
\hline \multicolumn{3}{|l|}{ T2-T12 } \\
\hline R1 Group $1(n=470)$ & 32 & 32 \\
\hline$R 2+3$ Group $1(n=470)$ & 42 & 93 \\
\hline R1 Group $2(n=466)$ & 44 & 103 \\
\hline$R 2+3$ Group $2(n=466)$ & 47 & 122 \\
\hline \multicolumn{3}{|l|}{ L1-L3 } \\
\hline R1 Group $1(n=470)$ & 5 & 5 \\
\hline $\mathrm{R} 2+3$ Group $1(n=470)$ & 36 & 50 \\
\hline R1 Group $2(n=466)$ & 27 & 37 \\
\hline$R 2+3$ Group $2(n=466)$ & 29 & 46 \\
\hline
\end{tabular}

Table 1 Number of patients with fractures having a Genet severity $>1$, Genet severity $>0$ among all patients in the entire spinal column (T2-L3), the thoracic spinal column (T2-T12) and the lumbar spine (L1-L3) in groups 1 and 2 , evaluated by reader 1 (R1) and reader $2+3(R 2+3)$.

Table 2 Number of fractures of the individual vertebrae in groups $1(n=470)$ and $2(n=466)$. The evaluations by $R 2+3$ were used as gold standard.

\begin{tabular}{|c|c|c|c|c|c|c|c|c|c|c|c|c|c|c|c|}
\hline & T2 & T3 & T4 & T5 & T6 & $\mathrm{T7}$ & T8 & T9 & $\mathrm{T} 10$ & T11 & T12 & L1 & L2 & L3 & Total \\
\hline R1 Group 1 , severity >0 & 0 & 0 & 0 & 1 & 6 & 9 & 12 & 4 & 7 & 7 & 11 & 5 & 1 & 0 & 63 \\
\hline$R 2+3$ Group 1 , severity $>0$ & 0 & 1 & 3 & 7 & 14 & 25 & 29 & 15 & 15 & 17 & 35 & 35 & 23 & 6 & 225 \\
\hline R1 Group 1, severity >1 & 0 & 0 & 0 & 1 & 6 & 9 & 11 & 4 & 7 & 6 & 11 & 5 & 1 & 0 & 61 \\
\hline $\mathrm{R} 2+3$ Group 1 , severity > 1 & 0 & 0 & 2 & 3 & 7 & 8 & 11 & 4 & 8 & 5 & 19 & 22 & 15 & 5 & 109 \\
\hline R1 Group 2, severity >0 & 0 & 4 & 0 & 9 & 22 & 27 & 26 & 25 & 12 & 18 & 33 & 30 & 15 & 3 & 224 \\
\hline $\mathrm{R} 2+3$ Group 2 , severity $>0$ & 0 & 4 & 1 & 11 & 24 & 36 & 31 & 30 & 14 & 22 & 37 & 38 & 17 & 3 & 268 \\
\hline R1 Group 2, severity > 1 & 0 & 2 & 0 & 2 & 6 & 8 & 13 & 9 & 7 & 10 & 18 & 21 & 9 & 1 & 106 \\
\hline R2 + 3 Group 2, severity > 1 & 0 & 2 & 0 & 3 & 7 & 8 & 15 & 11 & 6 & 12 & 17 & 23 & 9 & 1 & 114 \\
\hline
\end{tabular}




\begin{tabular}{|c|c|c|c|}
\hline & $\begin{array}{l}\text { simple percentage } \\
\text { agreement }\end{array}$ & kappa value & $\begin{array}{l}95 \% \text { confidence interval } \\
\text { for kappa value }\end{array}$ \\
\hline \multicolumn{4}{|c|}{ T2-L3 with a Genant severity > 1} \\
\hline group $1(n=67 / 470)$ & 89.4 & 0.448 & $0.322-0.573$ \\
\hline group $2(n=67 / 466)$ & 98.9 & 0.953 & $0.912-0.994$ \\
\hline \multicolumn{4}{|c|}{ T2-L3 with a Genant severity >0 } \\
\hline group $1(n=117 / 470)$ & 80.4 & 0.311 & $0.217-0.405$ \\
\hline group $2(n=140 / 466)$ & 95.3 & 0.882 & $0.835-0.929$ \\
\hline \multicolumn{4}{|c|}{ T2-T12 with a Genant severity >1 } \\
\hline group $1(n=42 / 470)$ & 94.0 & 0.590 & $0.453-0.727$ \\
\hline group $2(n=47 / 466)$ & 98.9 & 0.939 & $0.866-0.992$ \\
\hline \multicolumn{4}{|c|}{ T2-T12 with a Genant severity >0 } \\
\hline group $1(n=93 / 470)$ & 85.3 & 0.386 & $0.278-0.494$ \\
\hline group $2(n=122 / 466)$ & 95.5 & 0.877 & $0.826-0.928$ \\
\hline \multicolumn{4}{|c|}{ L1-L3 with a Genant severity > 1} \\
\hline group $1(n=36 / 470)$ & 93.0 & 0.180 & $0.023-0.337$ \\
\hline group $2(n=29 / 466)$ & 99.6 & 0.962 & $0.909-1.000$ \\
\hline \multicolumn{4}{|c|}{ L1-L3 with a Genant severity >0 } \\
\hline group $1(n=50 / 470)$ & 90.4 & 0.166 & $0.039-0.293$ \\
\hline group $2(n=46 / 466)$ & 98.1 & 0.881 & $0.805-0.957$ \\
\hline
\end{tabular}

Table 3 Simple percent agreement between R1 and R2 + 3, kappa value with $95 \%$ confidence interval for patients with fractures having Genant severity $>1$ and Genant severity $>0$ in groups 1 and 2 for the entire spinal column (T2-L3), the thoracic spinal column (T2-T12) and the lumbar spinal column (L1-L3). exhibited no significant difference ( $\bullet$ Table 2$)$. The total number of fractured vertebrae (Genant severity >0) from T2 through L3 in groups 1 and 2 was 225 and 268, respectively, $(p=0.250)$, with moderate/severe fractures (Genant severity $>1$ ) in each group being 109 and 114 , respectively $(p=0.261)$. Overall, most fractures occurred in L1 (73/936), followed by T12 (72/936) and T7 (61/936) ( $\bullet$ Table 2).

The simple agreement between $\mathrm{R} 1$ and $\mathrm{R} 2+3$ for all fractures (Genant severity >0) was $80.4 \%$ in Group 1 and $95.3 \%$ in Group 2 ( $\bullet$ Table 3 ). The kappa value increased from $\mathrm{K}=0.311(95 \% \mathrm{CI}: 0.217-0.405)$ in the sense of a "fair agreement" in Group 1 to $\mathrm{k}=0.882$ (95\% CI: 0,835-0,929) in the sense of an "almost perfect agreement" in Group 2 ( Tab.3). Similar results were observed for moderate/severe fractures (Genant severity $>1$ ) ( $\bullet$ Table 3 ). For Group 1 , $\mathrm{R} 1$ demonstrated a better detection rate for thoracic than lumbar vertebrae. In the thoracic spinal column (T2-T12) a $K=0,386$ (95\% CI: 0,278-0,494) in the sense of "fair agreement" was ascertained for all fractures, while only a $\mathrm{K}=0,166(95 \% \mathrm{CI}: 0,039-0,293)$ in the sense of "slight agreement" was yielded for the lumbar spinal column. R1's superior detection rate in the thoracic spinal column over the lumbar spinal column for group 1 was also observed for moderate/severe fractures (Genant severity > 1) ( $\bullet$ Table 3). Following the training, however, k-values for both the thoracic and lumbar spinal columns were observed to rise to a similar level ("almost perfect agreement" with $\mathrm{K}=0.877(95 \% \mathrm{CI} 0.826-0.928)$ in the thoracic spinal column and $\mathrm{K}=0.881$ (95\% CI $0.805-0.957$ ) in the lumbar spinal column ( $\bullet$ Table 3, $\bullet$ Fig. 2, 3).

- Fig. 1 presents the frequencies of SFI ascertained by R1 and R2 +3 in groups 1 and 2. The differences in SFI between R1 and R2 + 3 were statistically significant for groups 1 and 2 prior to training $(\mathrm{p}<0.001)$.

The rate of false positives (vertebrae assessed as fractured by R1) was zero for the group examined prior to training. In the group examined following training, R1 evaluated a vertebrae as fractured with a Genant severity $=1$ in four cases (once each for T5, T6, T7, T11) and in a single instance as fractured with a Genant severity $=2$ (L2), whereas R2 + 3 had not assessed these vertebrae as fractured.

\section{Discussion}

This study shows that even a brief, specialized training is sufficient for improving a radiologist's perceptive faculty for detecting and documenting prevalent osteoporotic spinal column fractures through routine chest radiographs. With multiple studies having shown regular radiological training to be inadequate for this purpose, the IOF has developed informational material for a training program of this type and has made it available for downloading [20].

Women with prevalent osteoporotic vertebral fractures are five times more at risk of incurring additional vertebral fractures and are at double the risk of suffering a hip fracture. They additionally have an eight times higher mortality rate [24-26]. One in five women with an osteoporotic vertebral fracture will suffer another vertebral fracture within a year [7]. Early diagnostic radiology coupled with subsequent appropriate therapy helps prevent further fractures. Effective therapies are widely available and can reduce vertebral fractures, femoral neck fractures and other fractures by $30 \%$ to $65 \%$ [27]. Precise documentation of prevalent osteoporotic vertebral fractures when performing X-ray examinations is therefore very important.

Lumbar and thoracic spinal column radiographs are the standard examination in diagnosing vertebral fractures in patients exhibiting suggestive symptoms (e.g. pain in the thoracic or lumbar spinal columns, decrease in body height or thoracic kyphosis) [28]. Furthermore, osteoporotic vertebral fractures can be evaluated through lateral "Dual-energy X-ray absorptiometry” (DXA)-scans, which have been found to be highly sensitive ( $>80 \%$ ) in detecting moderate/ severe vertebral deformations and have shown excellent negative prognostic values (>90\%) in differentiating persons without vertebral deformations from those with vertebral deformations. This method is referred to as "vertebral fracture analysis" (VFA) [29, 30]. On the other hand, osteo- 

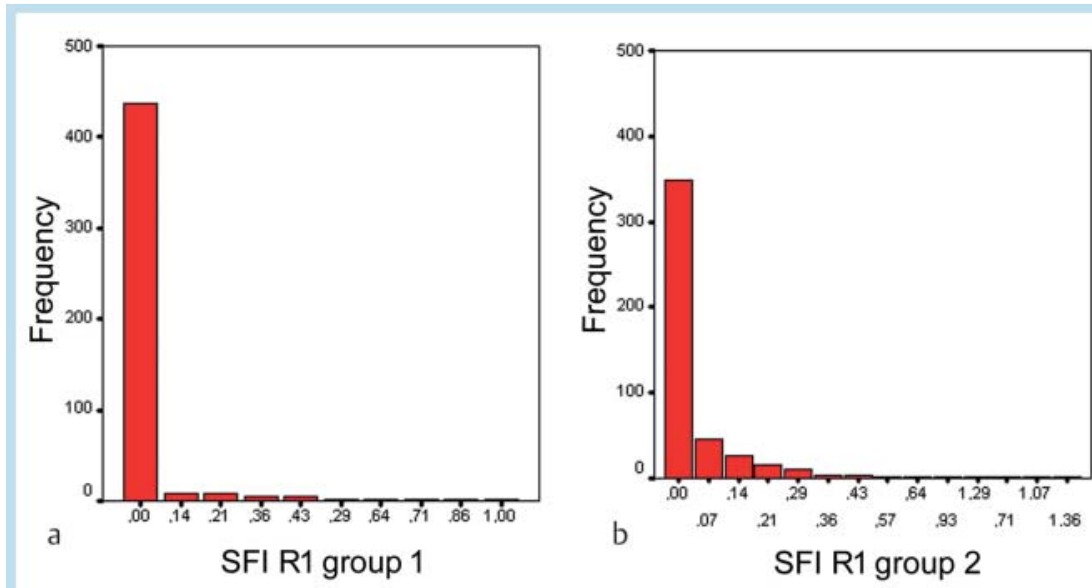

Fig. $1 \mathrm{SFI}$ scores compared to the absolute number of $R 1$ and $R 2+R 3$ in groups 1 and 2 . The differences between $R 1$ and $R 2+R 3$ were evaluated in both groups using the Wilcoxon sign rank test.,
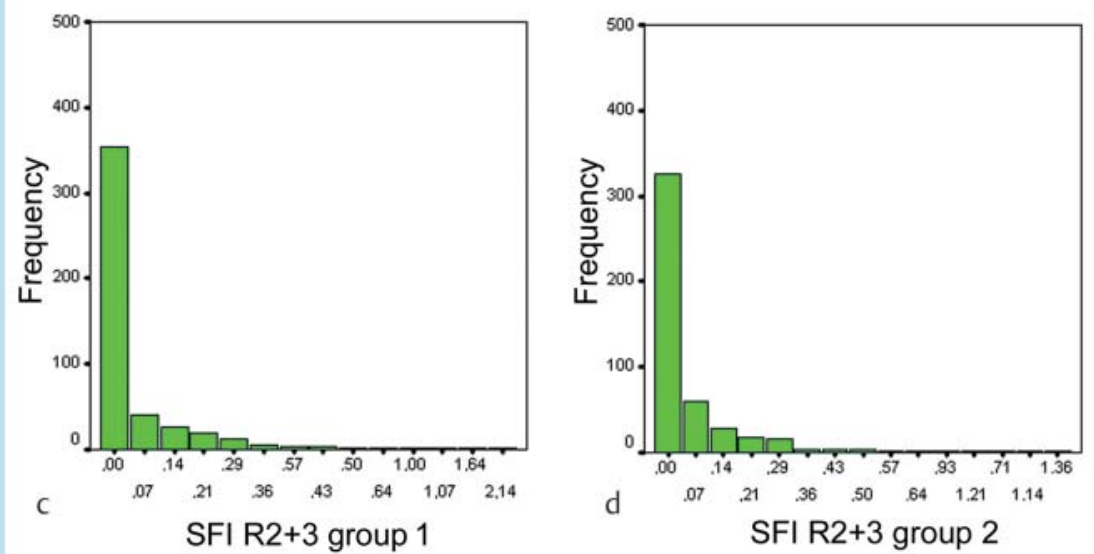

porotic vertebral fractures can be detected in asymptomatic persons primarily by non-dedicated imaging examinations. These examinations include for one, MDCT, where sagittal reformations in particular can be very effective in evaluating osteoporotic vertebral fractures [31, 32]. At the other end, chest radiographs - the most frequently performed radiographic procedure - have the potential of serving as a screening tool for prevalent osteoporotic vertebral fractures. However, osteoporotic vertebral fractures imaged in chest radiographs are often inadequately documented as earlier studies have reported [12-17].

The inadequate diagnosis of osteoporotic vertebral fractures is a global problem that is based partly on inadequate perception, the use of ambiguous terminology in $\mathrm{x}$-ray reports or a combination of both [14]. Osteoporotic vertebral fractures were clearly underdiagnosed in the x-ray reports generated in a multicentric, multinational study on women with osteoporosis $(\mathrm{n}=2451)$ in which 789 women $(32 \%)$ had at least one vertebral fracture at the beginning of the study. Verified deviations $(n=350)$ between local and central reporting of undetected vertebral fractures (68\%) or the use of unclear terminology in the local radiograph report $(32 \%)$ resulted in a false-negative rate of $34 \%$. Inadequate diagnosis of osteoporotic vertebral fractures was observed in all geographic regions (false-negative rates: North America 45.2\%, Latin America 46.5\%, Europe/South Africa/ Australia $29.5 \%$ ), with the global false-positive rate being $5 \%$ [14].

The aim of the IOF/ESSR Vertebral Fracture Initiative is to strengthen understanding on the significance of osteoporo- sis and to increase the perceptive faculties of radiologists in detecting vertebral fractures. An additional goal is to ensure that vertebral fractures are correctly documented with the term "fractured" in an effort to prevent ambiguities arising from other terminology. A similar quality assurance approach is also employed in breast cancer testing, for example [33].

In our study, a radiologist demonstrated marked improvement in her proficiency in documenting fractures after participating in the training [20]. According to Landis et al. [23], the agreement between $\mathrm{R} 1$ and the reference standard (R2 +3 ) improved from minimal, low or moderate to very good and excellent for both the thoracic and lumbar spinal columns. Detection of mild osteoporotic fractures (Genant severity $=1$ ) in particular improved significantly. These fractures were not detected in the group prior to training. The primary reason for this may lie in the mere underestimation of mild fractures, given that the teaching initiative may have made the radiologist (R1) more conscientious in the detection of prevalent vertebral fractures during routine chest radiographs and the subsequent description thereof when completing the report. In one case in particular, confusion with degenerative changes prevented the fracture from being reported. R1's improved perceptive faculty for detecting vertebral fractures following the training is further evidenced by the fact that she reported a false-positive fracture in only five cases, whereas she reported no false-positive fractures prior to training. In any case, however, the SFI ascertained from T2 through L3 differed significantly between R1 and R2 + 3 even for Group 2 (after R1 un- 


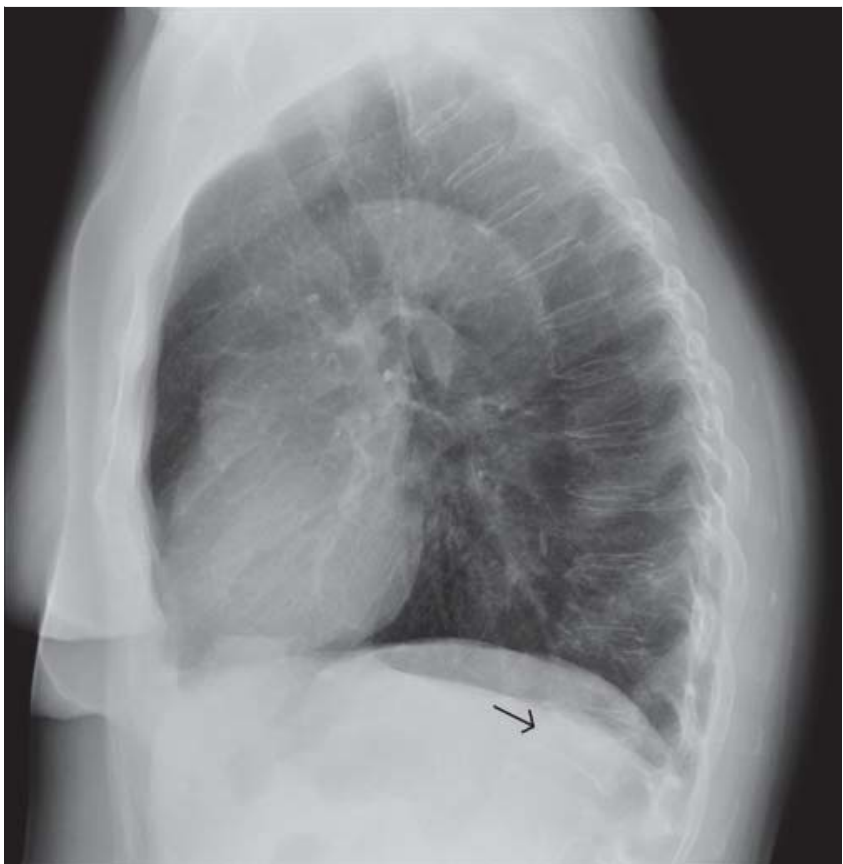

Fig. 2 71-year-old woman from group 1 (prior to training) with osteoporotic fracture (Genant severity $=2$ ) at L1 (black arrow) on a routine lateral chest radiograph that was not documented by $\mathrm{R} 1$.

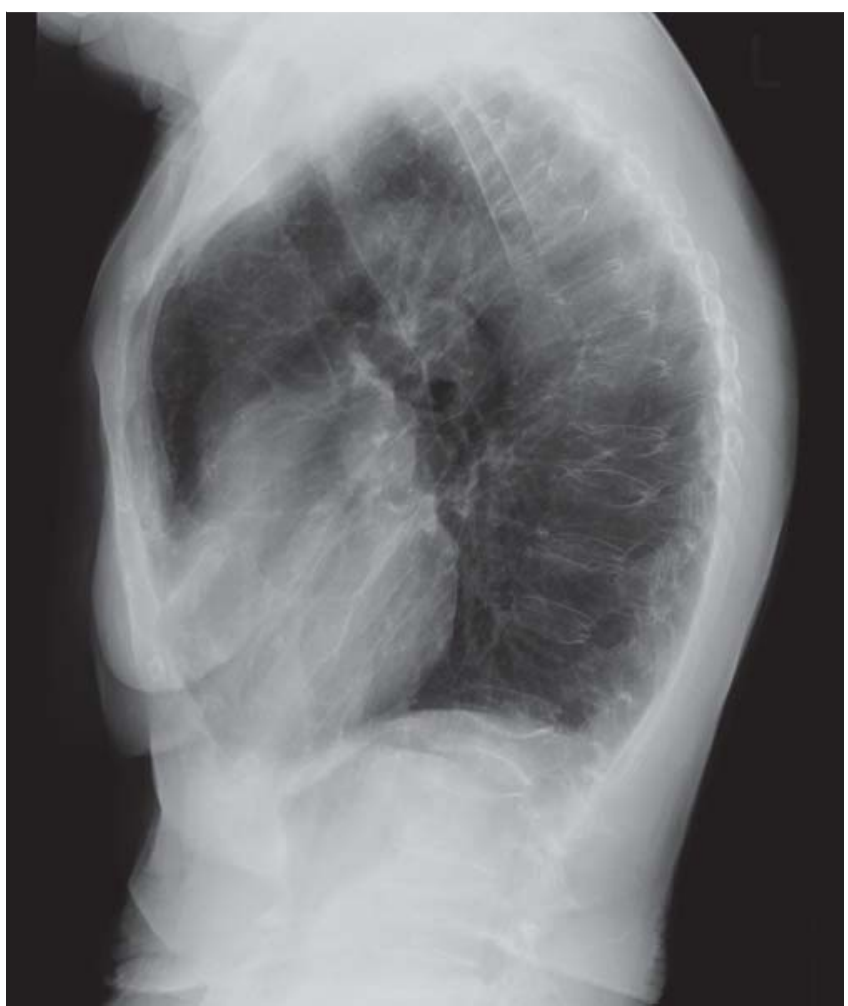

Fig. 3 63-year-old woman with multiple vertebral fractures (Genant severity = 1: T5, T6, T12, L3; Genant severity $=2:$ T3, T7, T11; Genant severity $=3$ : $\mathrm{T} 8, \mathrm{~T} 10, \mathrm{~L} 2$ ) that was correctly reported by $\mathrm{R} 1$ after the training (group 2).

derwent training). It can thus be concluded that while the teaching initiative facilitated improved detection of patients with osteoporotic vertebral fractures (see rise in kappa val- ues), R1 apparently continued to diagnose either the severity or, when multiple fractures were prevalent, only a portion of the fractures (and thus ultimately SFI) with significant discrepancy compared to $\mathrm{R} 2+3$ even after the training. R1's overall better and more assured detection of vertebral fractures following the training contributed to increased professional satisfaction [34].

Our study had several limitations. First, the detection of secondary findings in chest radiographs (e.g. a vertebral fracture) by a young radiologist improved on a case-by-case basis. The improved performance in the group following the training may have been influenced to some extent by the radiologist's overall better performance, which can be attributed to the extended period of the radiological training. Secondly, our study selected two radiologists as reference standard. We cannot rule out the possibility that the two certified radiologists also overlooked a prevalent vertebral fracture. Thirdly, our study group consisted entirely of postmenopausal women. However, similar results would have to be expected for a male study group as well. The comparison between R1's results prior to and following training may be distorted by a differing prevalence and distribution of osteoporotic vertebral fractures in groups 1 and 2 . We did not find any statistically significant differences in terms of the prevalence and distribution of osteoporotic vertebral fractures between groups 1 and 2 . While a distortion of the comparison between R1's results prior to and following training would thus appear to be minor, it of course cannot be ruled out entirely.

In summary, specific training is imperative for optimizing the perception and documentation of osteoporotic vertebral fractures when performing routine chest radiographs. The teaching initiative of the IOF/ESSR is well suited for this purpose and thus contributes to bringing about adequate therapy for patients with prevalent osteoporotic vertebral fractures.

\section{References}

1 Sanchez-Riera L, Wilson N, Kamalaraj $N$ et al. Osteoporosis and fragility fractures. Best practice \& research Clinical rheumatology 2010; 24: $793-810$

2 Nih Consensus Development Panel on Osteoporosis Prevention D, Therapy. Osteoporosis prevention, diagnosis, and therapy. JAMA: the journal of the American Medical Association 2001; 285: 785 - 795

3 Cole ZA, Dennison EM, Cooper C. Osteoporosis epidemiology update. Current rheumatology reports 2008; 10: 92 -96

4 Boonen S, Autier P, Barette $M$ et al. Functional outcome and quality of life following hip fracture in elderly women: a prospective controlled study. Osteoporosis international: a journal established as result of cooperation between the European Foundation for Osteoporosis and the National Osteoporosis Foundation of the USA 2004; 15: 87-94

5 Altenbernd J, Bitu S, Lemburg S et al. Wirbelfrakturen bei Patienten mit Spondylitis ankylosans: Eine retrospektive Analyse von 66 Patienten. Fortschr Röntgenstr 2009; 181: 45 -53

6 Neumann A, Wuerfel J, Hunold P. „Keilwirbel verkehrt 'rum” - eine ungewöhnliche Komplikation der pathomechanistischen Kaskade Ankylosierende Spondylitis (AS) - Osteoporose - Wirbelkörperfraktur. Fortschr Röntgenstr 2011; 183: 564-566

7 Lindsay R, Silverman SL, Cooper C et al. Risk of new vertebral fracture in the year following a fracture. JAMA: the journal of the American Medical Association 2001; 285: 320-323

8 Ross PD. Clinical consequences of vertebral fractures. The American journal of medicine 1997; 103: 30S-42S; discussion 42S-43S

9 Melton LJ 3rd. Epidemiology of spinal osteoporosis. Spine 1997; 22: $2 \mathrm{~S}-11 \mathrm{~S}$ 
10 World Health Organization Collaborating Centre for Metabolic Bone Diseases. University of Sheffield, UK; 2008, http://www.sheffield.ac. uk/FRAX/

11 Dachverband Osteologie e.V. 2009, http://www.dv-osteologie.org/uploads/leitlinien/DVOLeitlinie\%202009\%20Langfassung_Druck.pdf

$12 \mathrm{Kim} N$, Rowe BH, Raymond G et al. Underreporting of vertebral fractures on routine chest radiography. American journal of roentgenology 2004; 182: $297-300$

13 Gehlbach SH, Bigelow C, Heimisdottir M et al. Recognition of vertebral fracture in a clinical setting. Osteoporosis international: a journal established as result of cooperation between the European Foundation for Osteoporosis and the National Osteoporosis Foundation of the USA 2000; 11: $577-582$

14 Delmas PD, van de Langerijt $L$, Watts NB et al. Underdiagnosis of vertebral fractures is a worldwide problem: the IMPACT study. Journal of bone and mineral research: the official journal of the American Society for Bone and Mineral Research 2005; 20: 557-563

15 Oschatz E, Prosch H, Kohansal R et al. COPD and osteoporosis: detection and grading of vertebral fractures on lateral chest radiography. Journal of thoracic imaging 2009; 24: 212-215

16 Kroth PJ, Murray MD, McDonald CJ. Undertreatment of osteoporosis in women, based on detection of vertebral compression fractures on chest radiography. The American journal of geriatric pharmacotherapy 2004; 2: 112-118

17 Fechtenbaum J, Cropet C, Kolta S et al. Reporting of vertebral fractures on spine X-rays. Osteoporosis international: a journal established as result of cooperation between the European Foundation for Osteoporosis and the National Osteoporosis Foundation of the USA 2005; 16: $1823-1826$

18 Kotter E, Weisser G, Walz M et al. Die Arbeitsgemeinschaft Informationstechnologie stellt sich vor. Fortschr Röntgenstr 2011; 183: 1111 1113

19 Lentle BC, Brown JP, Khan A et al. Recognizing and reporting vertebral fractures: reducing the risk of future osteoporotic fractures. Canadian Association of Radiologists journal = Journal l'Association canadienne des radiologistes 2007; 58: $27-36$

20 International Osteoporosis Foundation and European Society of Musculoskeletal Radiology. http://www.slideserve.com/celina/international-osteoporosis-foundation-european-society-of-musculoskeletal-radiology

21 World Medical Association I. Declaration of Helsinki - ethical principles for medical research involving human subjects. 1964

22 Genant $H K, W u C Y$, van Kuijk $C$ et al. Vertebral fracture assessment using a semiquantitative technique. Journal of bone and mineral re- search: the official journal of the American Society for Bone and Mineral Research 1993; 8: 1137-1148

23 Landis JR, Koch GG. The measurement of observer agreement for categorical data. Biometrics 1977; 33: 159-174

24 Black DM, Arden NK, Palermo L et al. Prevalent vertebral deformities predict hip fractures and new vertebral deformities but not wrist fractures. Study of Osteoporotic Fractures Research Group. Journal of bone and mineral research: the official journal of the American Society for Bone and Mineral Research 1999; 14: 821-828

25 Melton LJ 3rd, Atkinson EJ, Cooper C et al. Vertebral fractures predict subsequent fractures. Osteoporosis international: a journal established as result of cooperation between the European Foundation for Osteoporosis and the National Osteoporosis Foundation of the USA 1999; 10: $214-221$

26 Cauley JA, Thompson DE, Ensrud KC et al. Risk of mortality following clinical fractures. Osteoporosis international: a journal established as result of cooperation between the European Foundation for Osteoporosis and the National Osteoporosis Foundation of the USA 2000; 11: $556-561$

27 Delmas PD. Treatment of postmenopausal osteoporosis. Lancet 2002; 359: $2018-2026$

28 Grados F, Fechtenbaum J, Flipon E et al. Radiographic methods for evaluating osteoporotic vertebral fractures. Joint, bone, spine: revue du rhumatisme 2009; 76: $241-247$

29 Bazzocchi A, Spinnato P, Fuzzi $F$ et al. Vertebral fracture assessment by new dual-energy X-ray absorptiometry. Bone 2012; 50: 836-841

30 El Maghraoui A, Mounach A, Rezqi A et al. Vertebral fracture assessment in asymptomatic men and its impact on management. Bone 2012; 50: $853-857$

31 Bauer JS, Muller D, Ambekar A et al. Detection of osteoporotic vertebral fractures using multidetector CT. Osteoporosis international: a journal established as result of cooperation between the European Foundation for Osteoporosis and the National Osteoporosis Foundation of the USA 2006; 17: 608-615

32 Williams AL, Al-Busaidi A, Sparrow PJ et al. Under-reporting of osteoporotic vertebral fractures on computed tomography. European journal of radiology 2009; 69: 179-183

33 Waldmann A, Adrich S, Eisemann $N$ et al. Struktur- und Prozessqualitat in der qualitatsgesicherten Mammadiagnostik in Schleswig-Holstein. Fortschr Röntgenstr 2012; 184: 113-121

34 Beitzel KI, Ertl L, Grosse C et al. Berufszufriedenheit von Radiologen in Deutschland - aktueller Stand. Fortschr Röntgenstr 2011; 183: 749 757 